\title{
Transurethral Resection of Prostate (TURP) and Vesicolithotomy for Large Bladder Stone in Single Session: The Third World Perspective
}

This article was published in the following Dove Press journal: Research and Reports in Urology

\section{Liaqat Ali \\ Asiya Hassan \\ Nasir Orakzai \\ Muhammad Shahzad \\ Ihsanullah Khan \\ Kifayat Tariq}

Department of Urology, Institute of Kidney Diseases HMC Peshawar,

Peshawar, Pakistan

\section{Video Abstract}

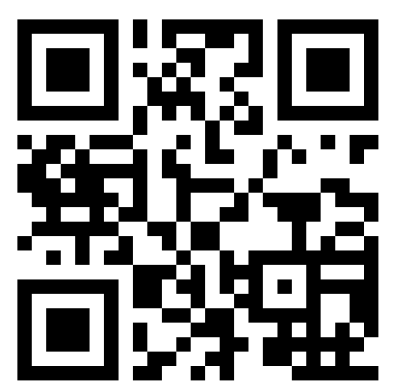

Point your SmartPhone at the code above. If you have a $Q R$ code reader the video abstract will appear. Or use: https://youtu.be/idNjakrGEJs
Correspondence: Liaqat Ali Institute of Kidney Diseases HMC

Peshawar, Phase 4, Hayatabad Medical

Complex, Peshawar, Khyber

Pukhtunkhwa, Pakistan

Tel +92-91-9217462

Email liaqat_99@yahoo.com
Objective: To study the effectiveness and safety of combined transurethral resection of prostate (TURP) and open vesicolithotomy in patients with benign prostatic hyperplasia and massive vesical calculi in a single session.

Methods: A descriptive study conducted at the Institute of Kidney and Diseases, Peshawar Pakistan from March 2013 till December 2019. In total, 43 patients were selected by nonprobability conventional sampling. We included patients with occluding enlarged prostate size of $30-60 \mathrm{~g}$ and bladder stones of more than $35 \mathrm{~mm}$ which was not amenable to cystolitholapaxy or cystolithotripsy. Conventional TURP followed by formal vesicolithotomy was performed in all patients in a single session. All the preoperative, perioperative and postoperative data were documented on structured Proforma. The data analysis was done on SPSS.

Results: The average age of the patients included was $65 \pm 7.5$ years. Mean size of prostate was $45.5 \pm 6.8 \mathrm{~g}$ and mean stone size was $38.4 \pm 4.2 \mathrm{~mm}$. The majority of patients $[60.4 \%$ $(n=26)]$ presented with refractory urinary retention. On average the operation time was 66.3 \pm 5.5 minutes. The mean resected volume of prostate was $23.5 \pm 6.8 \mathrm{~g}$ and the average hospital stay was $5.5 \pm 1.2$ days. Mean trial of removal of catheter was $5 \pm 0.6$ days. The trial of removal of catheter was successful in all patients. Significant improvement in maximum flow and average flow was recorded in all patients $(p=0.001)$. On average, the complication rate noted was $6.9 \%(n=3)$. There was no need for blood transfusion. No mortality was recorded in the study.

Conclusion: The combined TURP and open vesicolithotomy in a single session is an efficacious, safe and viable treatment modality for large bladder calculi secondary to moderately enlarged prostate.

Keywords: bladder outlet obstruction, benign prostatic hyperplasia, urinary bladder stone, transurethral resection of prostate, TURP

\section{Introduction}

Bbladder stones are solid crystal masses formed by minerals and proteins and are found in the urine. The stones are also known as bladder calculi or cystoliths. Stones can be formed in different parts of the urinary system. Stones are found in the bladder, an organ that holds the urine. Bladder stones can be associated with stones that are formed in other parts of the urinary tract, such as the kidneys. They are most common in men aged 50 and above. The prevalence of vesical calculi in Pakistan is $31 \%{ }^{1}$ 
Bladder stones are categorized as primary or secondary according to the etiology. Primary, ie indigenous vesical stones are linked to nutritional insufficiency and largely during childhood in Asian regions. ${ }^{2}$ Secondary bladder calculi are frequently associated with bladder outlet obstruction (BOO). The causes include prostatic enlargement, urethral stricture, bladder neck stenosis, and bladder dysfunction such as bladder diverticulum, neurogenic bladder diseases and cystoceles. ${ }^{3}$ Urinary tract infection favors the formation of struvite stones and foreign bodies, eg catheters and sutures, also promote the formation of bladder stones. ${ }^{4,5}$ Bladder augmentation surgery also leads to the development of vesical stones. A diet that lacks adequate fluid can lead to stones. Some stones are related to protein deficiency in the diet. Calcium levels in the urine may also be an issue of concern. ${ }^{6}$

In adults, uric acid is the most common composition of bladder stones and accounts for $50 \%$ of cases. Most of these patients have neither gout nor hyperuricemia. Other chemicals that are involved in the formation of bladder calculi are calcium oxalate and calcium phosphate, ammonium urate, cysteine and calcium ammonium magnesium phosphate. These calculi are also known as triple phosphate or struvite and are usually related to infection. The stones that are primarily calcium oxalate or calcium phosphate normally start as renal calculi, become stuck in the bladder and then evolve further coats of stone material until they grow too big and pass with difficulty and become symptomatic. Bladder stones are associated with bladder urothelial cancer.

Bladder stone formation is one of the complications of enlarged prostate and warrants surgical management. ${ }^{7,8}$ The surgical management of vesical calculi has evolved remarkably during the previous half century. Practices have transformed from the "blind" introduction of a crushing forceps into the bladder to open surgical removal or extracorporeal lithotripsy. ${ }^{9-13}$ It is explicitly straightforward that infravesical blockage ought to be rectified to remove any conditions that makes susceptible to bladder stone disease. Even though open surgery is foremost the best choice offered for extremely massive and large stone and also for patients that have large prostates, ${ }^{14-16}$ an open procedure might not be the appropriate choice for moderate and small occluding BPE; endoscopic surgery is the established and standard surgical management for the aforementioned condition. An endourological technique concurrently correcting both the infravesical obstruction and the stones is the best option for these patients. On these grounds, simultaneously combined treatment for bladder obstruction and vesical calculi has been suggested by numerous authors, stating the benefit of single anesthesia, a brief stay in hospital and cost -effectiveness. ${ }^{17-21}$ The endoscopic management of both prostate and stone is recommended and there is no doubt about it. $^{10,12}$ However, problems arise when the stone size is bigger than $30 \mathrm{~mm}$, which seems nearly impossible to be managed endoscopically even with a medium size prostate. Aron et al $2007^{15}$ reported cystolithotomy followed by transurethral resection of prostate. Santiago Richter et al ${ }^{14}$ also performed open vesicolithotomy followed by TURP. Currently, a Holmium laser is frequently used in the management of prostate and bladder stones. But its availability in financially constraint countries like Pakistan is a big issue in the management of BPH and giant bladder stones.

In this article we outline our practice in the management of large bladder stones with moderately enlarged prostate in the form of TURP followed by open vesicolithotomy in a single session to correct bladder outlet obstruction and explore whether this blend causes added morbidity and distress.

\section{Objective}

To study the effectiveness and safety of combined transurethral resection of prostate (TURP) and open vesicolithotomy in the patients with BPH and massive vesical stones in a single session.

\section{Operational Definitions Effectiveness}

By effectiveness we mean successful trial of removal of catheter on 5th postoperative day.

\section{Safety}

By safety we mean early postoperative complication rate, type of complication, need for blood transfusion, readmission and late postoperative complication.

\section{Method}

Study design: descriptive study; setting: Institute of Kidney and Diseases, Peshawar; duration: March 2013 till December 2019; sample size: 43 patients; technique: nonprobability convenience sampling. 


\section{Inclusion Criteria}

We included patients with occluding enlarged prostate size $30-60 \mathrm{~g}$ and bladder stones of more than $32 \mathrm{~mm}$ not amenable to cystolithlolapaxy or cystolithotripsy.

Conventional TURP was performed in all cases followed by open vesicolithotomy.

\section{Exclusion Criteria}

We excluded the patients with giant bladder stone with etiology other than BPH.

\section{Data Collection Procedure}

This study was approved by the Institutional Research and Ethical Board (IREB) of Institute of Kidney Diseases and all the participants provided informed consent in accordance with the declaration of Helsinki. A complete and pertinent history, relevant physical examination and appropriate investigations were performed in all patients. The size of prostate and stone was ascertained by ultrasonography. X-Ray KUB with full pelvis was performed in all the cases.

\section{Operative Procedure}

All procedures were performed in the main operating theatre. The procedures were performed under spinal or general anesthesia. Cystourethroscopy was performed in lithotomy position in all patients for confirmation of principal diagnosis and exclusion of associated pathologies. Conventional monopolar transurethral resection of prostate was performed using Blandy's technique of resection. After completion of resection, a three-way urethral catheter was inserted and irrigation with normal saline was started in all patients.

The position of the patient was then changed into the supine position. Patients were again scrubbed and draped. A minute $3-\mathrm{cm}$ skin crease incision was made two fingerbreadths above the pubis symphysis. Normal saline irrigation was temporarily stopped while incising the external rectus sheet for cysto-distension. The urinary bladder was then opened with a longitudinal incision. Stones were removed and the bladder was closed with Vicryl 2/0. The surgical wound was then closed in layers. All patients were followed up in the ward. The urinary catheters were removed on the 5th postoperative day and skin stitches on the 7th postoperative day. One of the giant bladder stones is shown in Figure 1. All preoperative, perioperative and postoperative data were documented on structured Proforma. The data analysis was done on SPSS.

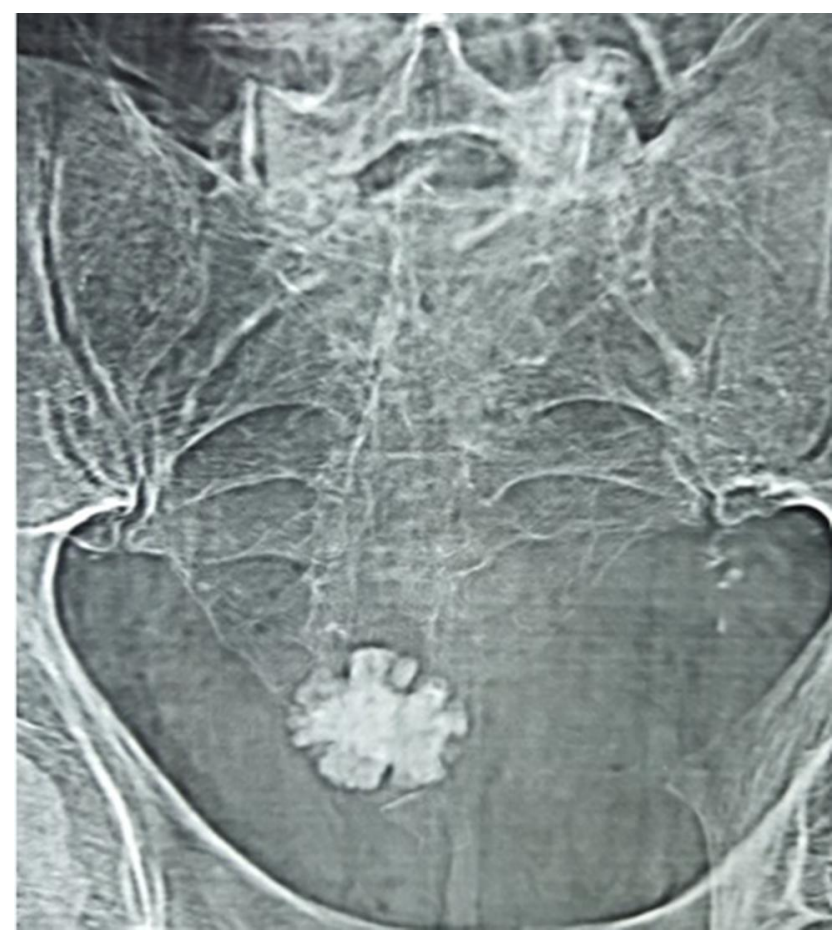

Figure I X-ray KUB showing large bladder stone.

\section{Results}

Data of 43 patients were analyzed. All of these patients were followed up for 12 months.

Basic characteristics like mean age, prostate size, stone size, operation time, resected volume and hospital stay are shown in Table 1. The pictures of the TURP procedure followed by vesicolithotomy are shown in Figures 1-3, respectively.

Mode of presentation was different in our study. The detail of clinical presentation is shown in Figure 4. All patients underwent TURP followed by formal vesicolithotomy. The effectiveness was labeled as a successful trial of catheter removal and change in uroflowmetry. The trial of catheter removal was successful in all patients at the 5th postoperative day. The change in uroflowmetry is shown

Table I The Basic Characteristics of Patients

\begin{tabular}{|l|l|l|}
\hline Variables & Value & SD \\
\hline Mean age (years) & 65.6 & 7.5 \\
Mean prostate size $(\mathrm{gm})$ & 45.5 & 6.8 \\
Mean stone size $(\mathrm{mm})$ & 38.4 & 4.2 \\
Mean operation time $(\mathrm{min})$ & 66 & 5.5 \\
Mean resected volume prostate & 23.5 & 6.8 \\
Mean hospital stay (days) & 5.5 & 1.2 \\
Median catheter removal (days) & 5 & 0.6 \\
\hline
\end{tabular}




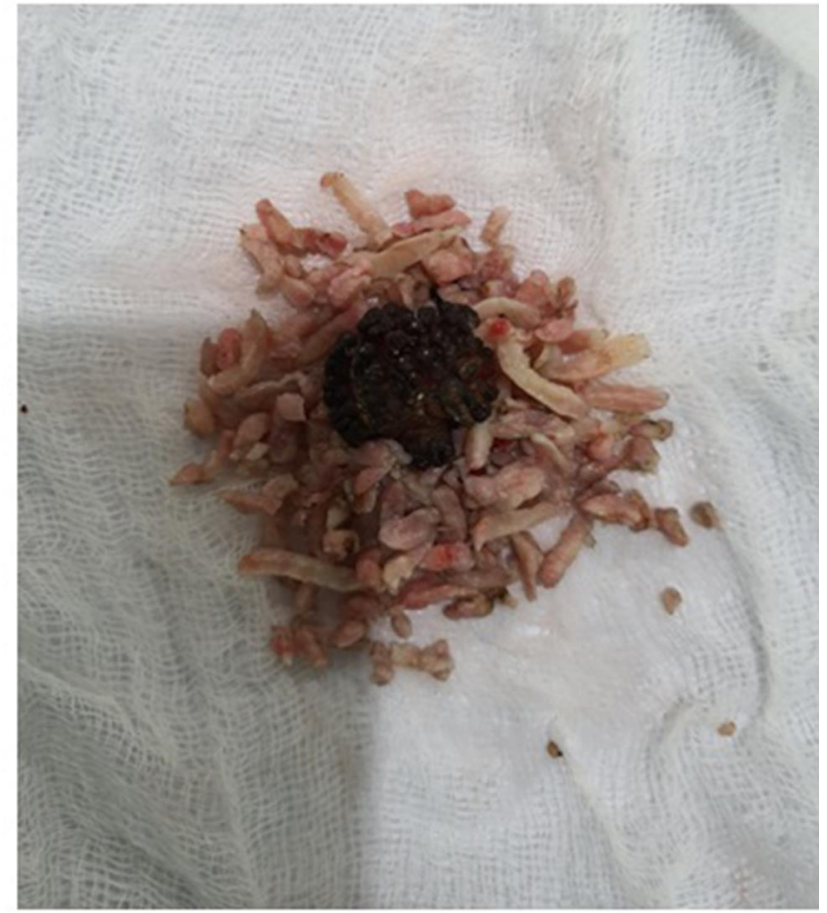

Figure 2 Prostatic chips and large bladder stone after combined TURP and vesicolithotomy.

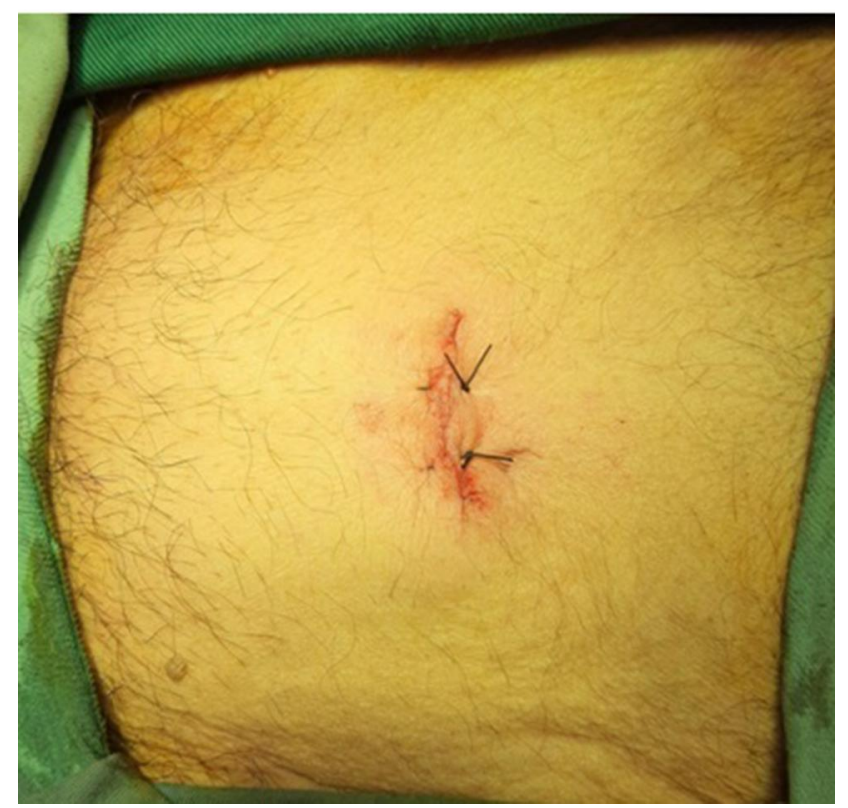

Figure 3 Patient with postoperative small suprapubic incision.

in Table 2. The TURP followed by vesicolithotomy was found to be safe in our study. The overall complication rate was $6.9 \%$ observed in three patients. The different complications are described in Figure 5. There was no mortality in the study. One patient required readmission due to febrile UTI. He was treated with parenteral antibiotics and was discharged after 72 hours. We did not record any urethral stricture or bladder neck stenosis in late follow-up.

\section{Discussion}

Bladder calculi comprised nearly $5 \%$ of urolithiasis. ${ }^{22}$ In the last half decade, with the refinement and development in diet, the prevalence of vesical calculus has spotted a radical shift. In addition to the advancement and improvement in the endourological contraptions the treatment of bladder stones has undergone an ample amount of evolution and sophistication.

Bladder stones are mostly associated with bladder outlet obstruction, and enlarged prostate is the most common cause in two-thirds of patients. Obstructive BPE is responsible for bladder calculi. Other conditions that culminate in bladder stones are: medical devices, neurogenic bladder, bladder inflammation, kidney stones, and bladder diverticula. Bladder outlet obstruction accounts for approximately $>75 \%$ of cases of secondary vesical calculi. ${ }^{22}$

Over the last five decades, the management of vesical stones has endured noteworthy evolution. The management encompasses a wide array of options ranging from non-invasive techniques such as chemolysis (chemical dissolution) and shockwave lithotripsy and invasive options consisting of open surgery (vesicolithotomy), transurethral cystolithotripsy and percutaneous cystolithotomy. ${ }^{11,23-25}$

As per EAU guidelines 2017, BPH results in the formation of bladder calculi. It is a complication of enlarged prostate and surgical treatment is firmly suggested, although some authors have interrogated this dogma by the use of shockwave lithotripsy for the managing BPH with bladder calculi. Milan-Rodriguez et al $^{26}$ described a 93\% stone clearance rate while managing 50 patients with combined bladder calculi and BPE in their study.

The transurethral and percutaneous techniques modernized the treatment of bladder calculi. The transurethral approach is an incisionless procedure and utilizes the natural orifice and aperture for entry; however, this is a lengthy and laborious procedure for the endourologist regardless of improvements in endourological instrumentation. Complication percentage supplementary to transurethral surgery falls in the range of $9 \%-25 \% .{ }^{27,28}$ Limitations and shortcomings consist of bleeding, loss of vision, urethral trauma, injury to mucosa, and lethal bladder perforation. A percutaneous approach to bladder stones circumvents the risk of urethral injury, with the acquisition of high stone clearance rates. The possible weakness and 


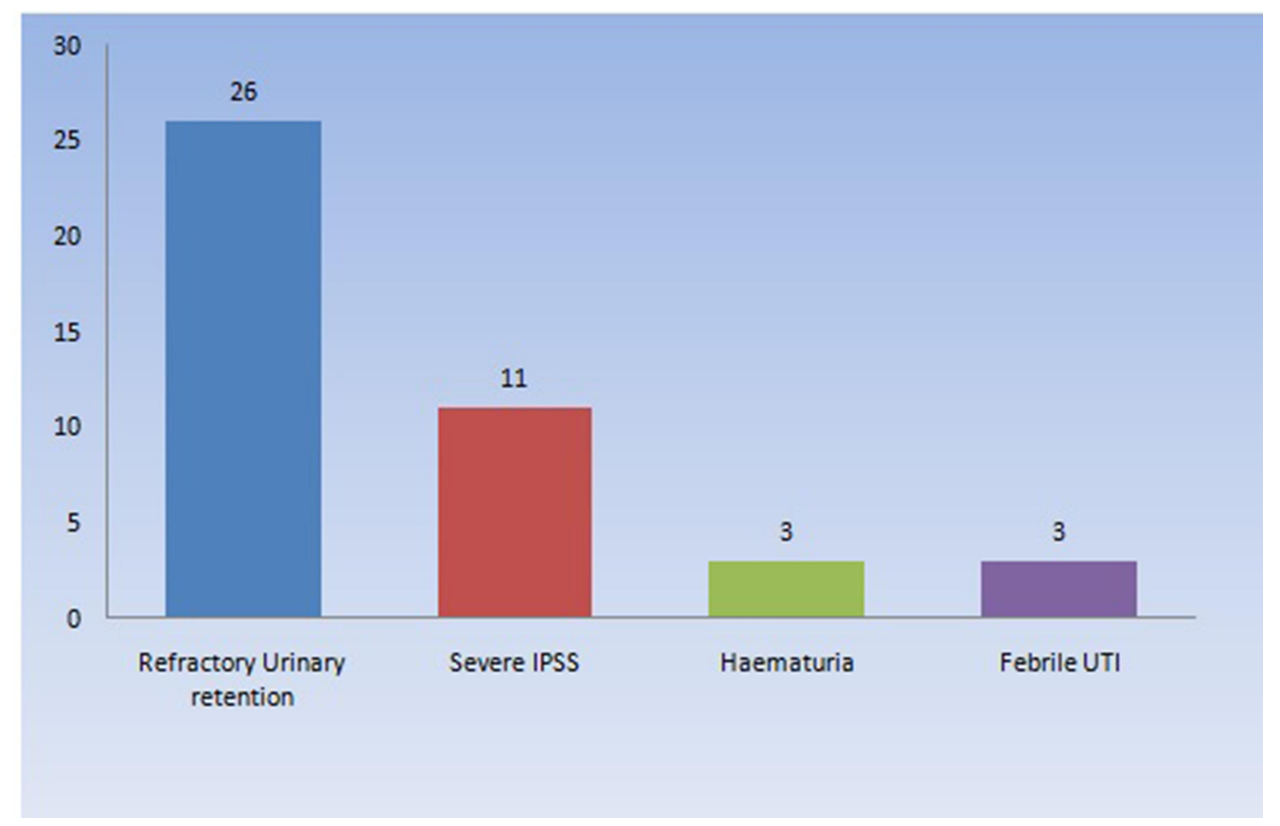

Figure 4 Mode of presentation of patients.

dereliction of this method are incision-associated injury to bowel/vascular injury, accidental and unintended loss of access, and extravasation. ${ }^{27-33}$

Management of bladder calculi in conjunction with enlarged prostate turns out to be a laborious, time-consuming and arduous procedure, particularly in patients with comorbidities who ought not sustain lengthy and extended procedures. Formally, these patients undergo surgery for vesical calculi either in the form of percutaneous or transurethral route and TURP afterwards. They may necessitate staged procedures for the same. Aron et $\mathrm{al}^{15}$ paralleled percutaneous vs transurethral cystolithotripsy and TURP for large prostates and large bladder stones, and determined that operating time was considerably less in those patients receiving percutaneous surgery for bladder stones.

In general, most bladder calculi and $\mathrm{BPH}$ procedures are executed endoscopically. Contra wise, if the stone is excessively large or too hard and tough or if the urethra of the patient is overly small (eg in the pediatric population)

Table 2 Change in Characteristics of Uroflowmetry

\begin{tabular}{|l|l|l|l|}
\hline $\begin{array}{l}\text { Uroflowmetry } \\
\text { Mean (SD) }(\mathrm{mL} / \mathrm{s})\end{array}$ & $\begin{array}{l}\text { Preoperative } \\
(n=13) *\end{array}$ & $\begin{array}{l}\text { Postoperative } \\
(n=43) * *\end{array}$ & $\begin{array}{l}\boldsymbol{P} \\
\text { value }\end{array}$ \\
\hline Max flow & $8.4 \pm 1.3$ & $24.7 \pm 4.7$ & $0.00 \mathrm{I}$ \\
Average Flow & $5.99 \pm 1.3$ & $16.1 \pm 3.5$ & $0.00 \mathrm{I}$ \\
\hline
\end{tabular}

Notes: *Patients who presented with symptoms other than urinary retention. **All patients in postoperative periods. or has been surgically transformed in a manner which makes access to the bladder difficult, an open or percutaneous suprapubic surgical route is superior. Sofer et $\mathrm{al}^{34}$ described the simultaneous combined practice of percutaneous and transurethral approaches in giant bladder stones.

In the treatment of bladder lithiasis and infravesical obstruction refractory to enlarged prostate, considerations must be given to the dimensions and composition of stone, the comorbidities of the patient, the existence of prior surgery and structural anomalies of lower urinary tract, the size of the prostate, cost as well as the availability of equipment. The eradication of causal factors is compulsory to therapeutic success. ${ }^{9}$

Aiming to inhibit new and novel stone formation and to encourage the disposal of stone particles, bladder outlet obstruction and bladder stones must be treated concurrently. In our study we use a novel technique of combined approach in the form of TURP followed by open vesicolithotomy in a single session to determine its effectiveness and safety. The benefits of this surgery embrace briskness, effortless extraction of numerous calculi in a single surgical procedure, the capability to remove calculi that are adherent to the mucosa and the potential to clear oversized stones which are too rigid or compact to break and fragment expeditiously through the transurethral or percutaneous approach. The stone clearance rate was $100 \%$ in our present surgical technique. The complications rate was also low, which includes skin and soft tissue infection 


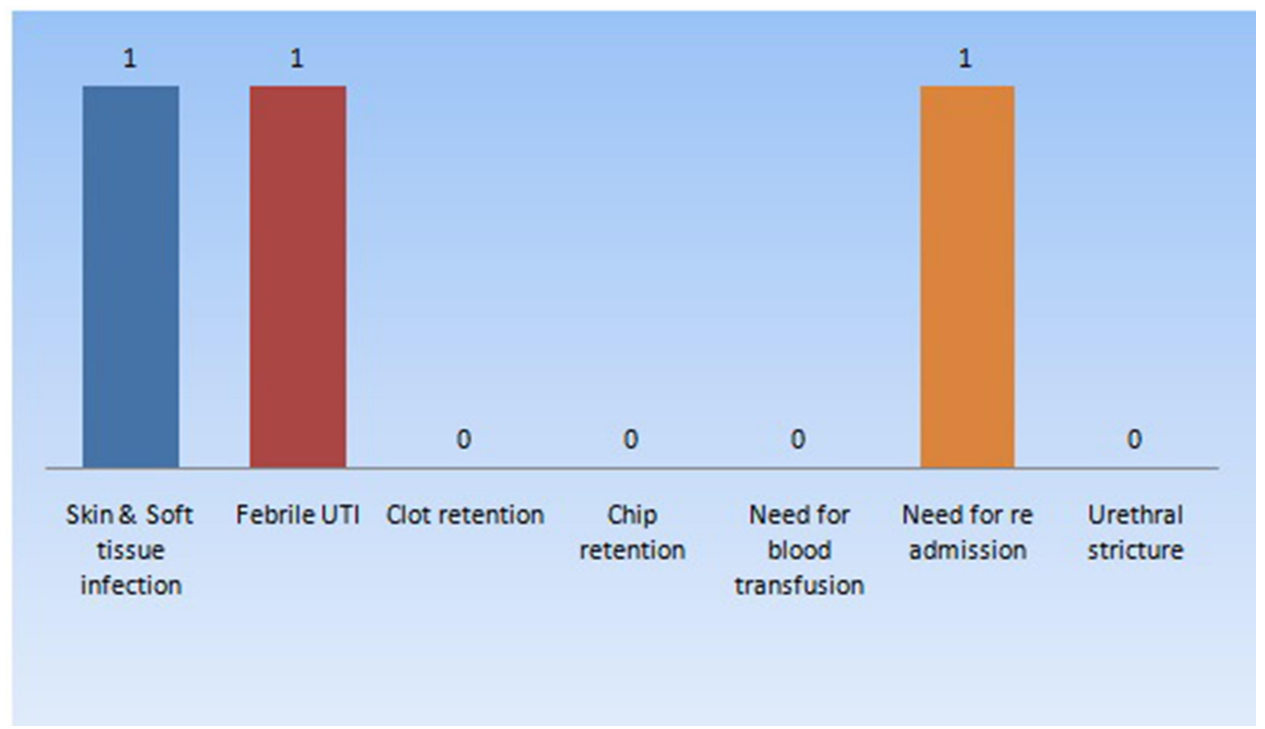

Figure 5 Complications of the combined TURP and vesicolithotomy.

and febrile urinary tract infection. However, there were no reported complications like urethral stricture and bladder neck stenosis. None of the patients in our study required blood transfusion. These findings are in accordance with the international literature.

The major disadvantages include postoperative pain, skin and soft tissue infection, UTI, longer hospital stay compared to endourological techniques and long duration of indwelling catheter when compared with international literature ( 2.6 vs 4.8 days).

Richter et al concluded that open vesicolithotomy carried out prior to TURP protracted the overall duration of the procedure an average of 18.4 minutes and hence TURP performed former to vesicolithotomy could save operative time. In our existing study, the average duration of surgery was 66 minutes as compared to 84 minutes as per the study conducted by Richter et al. ${ }^{14}$ Only one patient in our study developed skin and soft tissue infection, one patient developed febrile UTI and one required hospital readmission for parenteral antibiotics. None of the patients developed urethral stricture and bladder neck stenosis, which makes the combined approach a safer option for large bladder calculi and moderately enlarged prostate.

Contrasting and comparative studies among different treatment modalities are sparse and deficient. Bhatia et $\mathrm{al}^{13}$ stated managements of 128 patients with bladder stones, five patients sustained open surgery, 80 patients were treated endoscopically and 43 patients were dealt with extracorporeal shockwave lithotripsy (ESWL). The efficiency of open surgery was $100 \%$ in the elimination of bladder calculi, although it demanded a longer hospital stay on average of 5.2 days. The endoscopic lithotripsy has led to the maximum complication rate $(25 \%)$, comprising bladder perforation, urethral stenosis and bleeding. The overall hospital stay was of 2.4 days. ESWL was the one with a shorter hospital stay on an average of 20 hours; however, four $(9 \%)$ of the patients required repetitive sessions to achieve complete stone fragmentation. The large and hard calculi are managed by open vesicolithotomy.

At this time, many comparative studies between different treatment options are not available and further research should be carried out that will certainly devise the best and safest treatment modalities for the patients.

One of the limitations of our study is that this combined TURP followed by open vesicolithotomy for bladder calculi and infravesical obstruction is our experience and does not indicate standards. Also the sample size is small and the technique is nonprobability convenience sampling, hence it has selection bias. Therefore, randomized controlled trials are needed to confirm our conclusions and to determine the effectiveness and safety of combined TURP followed by open vesicolithotomy in a single session versus other available modalities of Holmium laser which were not available with us.

\section{Conclusion}

In the eon of endoscopic and minimally invasive surgery, combined TURP and open vesicolithotomy in a single session is a safer, effective and viable therapeutic modality 
in Third World countries where technologically advanced lasers are not available.

\section{Abbreviations}

Qmax, maximum urinary flow rate; $\mathrm{BPH}$, benign prostatic hyperplasia; BOO, bladder outlet obstruction; ESWL, extracorporeal shockwave lithotripsy; UTI, urinary tract infection; TURP, transurethral resection of prostate.

\section{Disclosure}

The authors report no conflicts of interest for this work.

\section{References}

1. Available from: https://www.researchgate.net/publication/ 235761560_Epidemiology_of_Stone_Disease_in_Pakistan. Accessed October 26, 2020.

2. Van Reen R. Geographical and Nutritional Aspects of Endemic Stones. Urinary Calculus. Littleton, Mass: PSG Publishing Co; 1981.

3. Huang W, Cao JJ, Cao M, et al. Risk factors for bladder calculi in patients with benign prostatic hyperplasia. Medicine. 2017;96(32): e7728. doi:10.1097/MD.0000000000007728

4. Rafique M. Intravesical foreign bodies: review and current management strategies. Urol J. 2008;5(4):223-231.

5. Rub R, Madeb R, Morgenstern S, Ben-Chaim J, Avidor Y. Development of a large bladder calculus on sutures used for pubic bone closure following extrophy repair. World J Urol. 2001;19 (4):261-262. doi:10.1007/s003450000163

6. Pozzi M, Locatelli F, Galbiati S, et al. Relationships between enteral nutrition facts and urinary stones in a cohort of pediatric patients in rehabilitation from severe acquired brain injury. Clin Nutr. 2019;38 (3):1240-1245. doi:10.1016/j.clnu.2018.05.005

7. Gratzke C, Bachmann A, Descazeaud A, et al. EAU Guidelines on the assessment of non-neurogenic male lower urinary tract symptoms including benign prostatic obstruction. Eur Urol. 2015;67:10991109. doi:10.1016/j.eururo.2014.12.038

8. McVary KT, Roehrborn CG, Avins AL, et al. Update on AUA guideline on the management of benign prostatic hyperplasia. $J$ Urol. 2011;185:1793-1803. doi:10.1016/j.juro.2011.01.074

9. Papatsoris AG, Varkarakis I, Dellis A, Deliveliotis C. Bladder lithiasis: from open surgery to lithotripsy. Urol Res. 2006;34(3):163-167. doi: $10.1007 / \mathrm{s} 00240-006-0045-5$

10. Philippou P, Moraitis K, Masood J, et al. The management of bladder lithiasis in the modern era of endourology. Urology. 2012;79:980986. doi:10.1016/j.urology.2011.09.014

11. Donaldson JF, Ruhayel Y, Skolarikos A, et al. Treatment of bladder stones in adults and children: a systematic review and meta-analysis on behalf of the European association of urology urolithiasis guideline panel. Eur Urol. 2019;76(3):352-367. doi:10.1016/j.eururo.20 19.06.018

12. Abergel S, Peyronnet B, Seguin P, Bensalah K, Traxer O, Freund Y. Management of urinary stone disease in general practice: a French Delphi study. Eur J Gen Pract. 2016;22(2):103-110. doi:10.3109/ 13814788.2016.1149568

13. Bhatia V, Biyani CS. Vesical lithiasis: open surgery versus cystolithotripsy versus extracorporeal shock wave therapy. J Urol. 1994;151 (3):660-662. doi:10.1016/S0022-5347(17)35041-3

14. Richter S, Ringel A, Sluzker D. Combined cystolithotomy and transurethral resection of prostate: best management of infravesical obstruction and massive or multiple bladder stones. Urology. 2002;59(5):688-691. doi:10.1016/S0090-4295(02)01507-8
15. Aron M, Goel R, Gautam G, Seth A, Gupta NP. Percutaneous versus transurethral cystolithotripsy and TURP for large prostates and large vesical calculi: refinement of technique and updated data. Int Urol Nephrol. 2007;39:173-177. doi:10.1007/s11255-005-0247-8

16. Freiha FS, et al. Open bladder surgery. In: Walsh PC, Retik AB, Stamey TA, editors. Campbell's Urology. Vol. 3. Philadelphia: WB Saunders;1992: 2750-2774.

17. de la Torre G, Barusso G, Chernobilsky V, et al. Outpatient simultaneous treatment of benign prostatic hyperplasia and bladder lithiasis with GreenLight ${ }^{\mathrm{TM}}$ and holmium laser. $J$ Endourol. 2012;26(2):164167. doi:10.1089/end.2011.0249

18. Nseyo UO, Rivard DJ, Garlick WB, et al. Management of bladder stones: should transurethral prostatic resection be performed in combination with cystolitholapaxy? Urology. 1987;29:265-267. doi:10. 1016/0090-4295(87)90067-7

19. Asci R, Aybex Z, Sarikaya S, et al. The management of vesical calculi with combined optical mechanical cystolithotripsy and transurethral prostatectomy: is it safe and effective? BJU Int. 1999;36:3236. doi:10.1046/j.1464-410x.1999.00030.x

20. Barnes RW, Bergman RT, Worton E. Litholapaxy vs. cystolithotomy. J Urol. 1963;89:680-681. doi:10.1016/S0022-5347(17)64620-2

21. Madhu SN, Sreeramulu PN, Girish H, Ratkal C. Combined TURP with bladder stones removal: in management of intravesical obstruction and large, multiple bladder stones. J Med Sci Res. 2016.

22. Drach GW, et al. Urinary lithiasis: etiology, diagnosis and medical management. In: Walsh PC, Retik AB, Stamey TA, editors. Campbell's Urology. Vol. 3. Philadelphia: WB Saunders;1992: 2085-2156.

23. Schwartz BF, Stoller ML. The vesical calculus. Urol Clin North Am. 2000;27:333-346. doi:10.1016/S0094-0143(05)70262-7

24. El-Halwagy S, Osman Y, Sheir KZ. Shock wave lithotripsy of vesical stones in patients with infravesical obstruction: an underused noninvasive approach. Urology. 2013;81(3):508-510. doi:10.1016/j. urology.2012.11.027

25. Razvi HA, Song TY, Denstedt JD. Management of vesical calculi: comparison of lithotripsy devices. J Endourol. 1996;10(6):559-563. doi:10.1089/end.1996.10.559

26. Millán-Rodríguez F, Izquierdo-Latorre F, Montlleó-González M, Rousaud-Barón F, Rousaud-Barón A, Villavicencio-Mavrich H. Treatment of bladder stones without associated prostate surgery: results of a prospective study. Urology. 2005;66(3):505-509. doi:10. 1016/j.urology.2005.03.072

27. Laird Harrison complications linked to TURP duration. Urology Times; November 20, 2018

28. Sathaye UV. Per-urethral endoscopic management of bladder stones: does size matter? $J$ Endourol. 2003;17(7):511-2; discussion 513. doi:10.1089/089277903769013694

29. Ener K, Agras K, Aldemir M, Okulu E, Kayigil O. The randomized comparison of two different endoscopic techniques in the management of large bladder stones: transurethral use of nephroscope or cystoscope? J Endourol. 2009;23(7):1151-1155. doi:10.1089/end.20 08.0647

30. Ikari O, Netto NR Jr, D'Ancona CA, Palma PC. Percutaneous treatment of bladder stones. J Urol. 1993;149(6):1499-1500. doi:10.1016/ S0022-5347(17)36426-1

31. Wollin TA, Singal RK, Whelan T, Dicecco R, Razvi HA, Denstedt JD. Percutaneous suprapubic cystolithotripsy for treatment of large bladder calculi. J Endourol. 1999;13(10):739-744. doi:10.1089/ end.1999.13.739

32. Demirel F, Cakan M, Yalginkaya F, Demirel AC, Aygün A, Altug UU. Percutaneous suprapubic cystolithotripsy approach: for whom? Why? $J$ Endourol. 2006;20(6):429-431. doi:10.1089/end.2006.20.429

33. Tzortzis V, Aravantinos E, Karatzas A, Mitsogiannis IC, Moutzouris G, Melekos MD. Percutaneous suprapubic cystolithotripsy under local anesthesia. Urology. 2006;68(1):38-41. doi:10.1016/j.urology. 2006.01.073 
34. Sofer M, Kaver I, Greenstein A, et al. Refinements in treatment of large bladder calculi: simultaneous percutaneous suprapubic and transurethral cystolithotripsy. Urology. 2004;64(4):651-654. doi:10. 1016/j.urology.2004.04.067
35. Al-Marhoon MS, Sarhan OM, Awad BA, Helmy T, Ghali A, Dawaba MS. Urology and nephrology center, Mansoura University, Mansoura, Egypt. J Urol. 2009;181(6):2684-7;discussion 2687-8. doi:10.1016/j. juro.2009.02.040

\section{Publish your work in this journal}

Research and Reports in Urology is an international, peer-reviewed, open access journal publishing original research, reports, editorials, reviews and commentaries on all aspects of adult and pediatric urology in the clinic and laboratory including the following topics: Pathology, pathophysiology of urological disease; Investigation and

Submit your manuscript here: https://www.dovepress.com/research-and-reports-in-urology-journal treatment of urological disease; Pharmacology of drugs used for the treatment of urological disease. The manuscript management system is completely online and includes a very quick and fair peer-review system, which is all easy to use. Visit http://www.dovepress.com/ testimonials.php to read real quotes from published authors. 